\title{
Hancock II bioprosthesis: A glance at the microscope in mid-long-term explants
}

\author{
Tomaso Bottio, ${ }^{a}$ Gaetano Thiene, ${ }^{\text {b }}$ Elena Pettenazzo, ${ }^{\mathrm{b}}$ Paolo lus, ${ }^{\mathrm{c}}$ Uberto Bortolotti, ${ }^{\mathrm{a}}$ Giulio Rizzoli, ${ }^{\mathrm{a}}$ Carlo Valfré, \\ Dino Casarotto, ${ }^{\mathrm{a}}$ and Marialuisa Valente ${ }^{\mathrm{b}}$
}
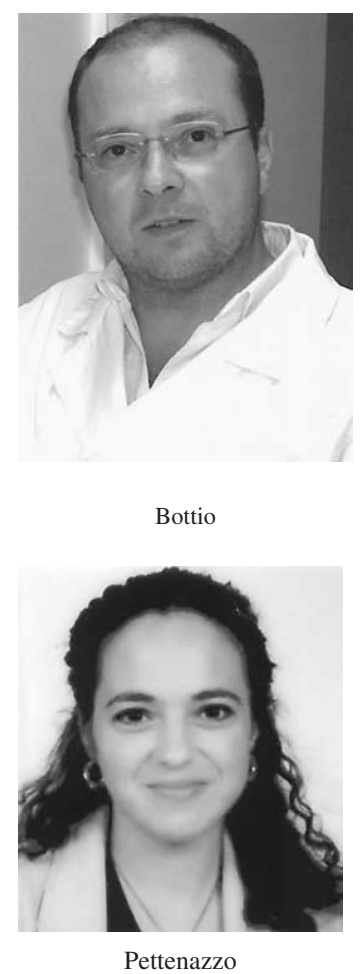

From the Departments of Cardiovascular Surgery, a and Pathological Anatomy, ${ }^{\mathrm{b}}$ University of Padua Medical School, Padua, Italy, and Division of Cardiac Surgery, ${ }^{\mathrm{c}} \mathrm{Ca}$ ' Foncello Hospital, Treviso, Italy.

The study was supported by a grant from Istituto Superiore di Sanità and Ministero Istruzione Universitá e Ricerca, Rome, Italy.

Received for publication Aug 2, 2002; revisions requested Sept 18, 2002; revisions received Nov 14, 2002; accepted for publication Nov 25, 2002.

Address for reprints: Marialuisa Valente, MD, Professor, Pathological Anatomy, Department of Pathological Anatomy, University of Padua Medical School, Via A Gabelli, 61 35121, Padova, Italy (E-mail: marialuisa.valente@unipd.it).

J Thorac Cardiovasc Surg 2003;126:99-105

Copyright (C) 2003 by The American Association for Thoracic Surgery

0022-5223/2003\$30.00+0

doi:10.1016/S0022-5223(03)00131-4
Background and Objectives: The Hancock II bioprosthesis is a second-generation porcine valve xenograft treated with the detergent sodium dodecyl sulphate (T6) to retard calcification. The aim of this investigation was to study the gross and microscopic features in Hancock II explants to assess the structural changes occurring with time.

Methods: Among 1382 Hancock II bioprostheses (701 isolated aortic, 421 isolated mitral, 130 double) implanted from 1983 to 1997 in 1252 patients, 22 (16 mitral, 6 aortic) were removed at reoperation until 1999 and were available for pathological investigation: infective endocarditis occurred in 5 and structural deterioration in 8 , whereas in the remaining 9 xenografts reoperation was performed for nonstructural valve deterioration (paravalvular leak in 4 and prophylactic replacement in 5). Morphological investigation consisted of gross examination and x-ray, histologic, immunohistochemistry, electron microscopic, and atomic absorption spectroscopic examination.

Results: The cause of structural valve deterioration was dystrophic calcification in 4 cases ( 1 aortic, 3 mitral; range of time graft was in place, 101 to 144 months), non-calcium-related tears in 3 cases (all mitral, range 121 to 163 months), and commissural dehiscence in 1 (aortic, range 156 months). Five of the nonstructural valve deterioration explants (range 42 to 122 months) showed only pinpoint mineralization at the commissures. Mean calcium content in nonstructural deterioration explants was $14.70 \pm 22.33$ versus $99.11 \pm 81.52 \mathrm{mg} / \mathrm{g}$ in explants with structural valve deterioration. Electron microscopic examination showed early nuclei of mineralization mostly consisting of calcospherulae upon cell debris. Local or diffuse lipid insudation was observed in all but 2 explants and consisted of cholesterol clefts, lipid droplets, and lipid-laden macrophages featuring foam cells. The lipid insudation was the most plausible cause of tearing in 2 explants.

Conclusions: These pathologic findings support the clinical results of a delayed occurrence of structural failure of Hancock II bioprostheses and a mitigation of mineralization by the anti-calcification treatment. However, other factors such as lipid insudation may come into play in the long term.

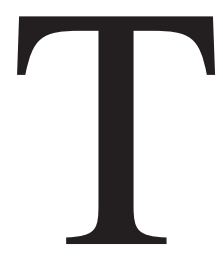

he Hancock (HCK) II porcine bioprosthesis was introduced in the clinical setting in 1982 with some modifications aimed to enhance performance versus the first-generation HCK Standard. The cusp tissue is treated with the detergent sodium dodecyl sulphate (T6) to retard calcification, and a low fixation pressure is employed in an effort to preserve collagen crimping. ${ }^{1}$

Clinical data suggested that this treatment was successful in significantly improving long-term performance. In particular, mid- and long-term clinical experience showed improved results in terms of durability and valve-related complications when compared with HCK Standard..$^{2-4}$ 
The aim of this investigation was to characterize the pathology and the mode of failure of HCK II explanted valves, with special reference to onset and progression of dystrophic calcification and other morphologic changes affecting long-term durability.

\section{Material and Methods}

From May 1983 to December 1997, 1382 HCK II bioprostheses were implanted in 1252 patients: 701 were isolated aortic, 421 isolated mitral, and 130 double-valve replacements. Twenty-two explants from 22 patients (11 men, 11 women, mean age $64.95 \pm$ 9.0, range 48 to 76 years) were available for pathological study because of reoperation performed in the time interval 1988 to 1999. The 22 explants were all of the explants removed during the study period at these institutions. Evidence of infective endocarditis was found in 5 explants, which were then ruled out from this study.

The remaining 17 HCK II xenografts (14 mitral and 3 aortic), explanted from 17 patients, mean age $64.29 \pm 10.14$ years and in place from 3 to 163 (mean $94.52 \pm 53.46$ months) underwent detailed morphological investigation. Indication for prosthetic replacement was incompetence in 9 cases and steno-incompetence in 3 , whereas 5 were removed prophylactically during other valve surgical procedures.

The protocol of investigation consisted of gross examination, photography of the specimens with a stereoscope, mammography x-ray for a semiquantitative analysis of $\mathrm{Ca}^{++}$deposits using scores of 0 to 4 , histology and immunohistochemistry, transmission and scanning electron microscopy, and atomic absorption spectroscopy, as reported elsewhere. ${ }^{5,6}$

\section{Statistics}

The incidence of structural valve deterioration (SVD) in aortic and mitral positions was compared with the Fisher exact test. The mean mineralization in SVD and non-SVD explants was compared with the $t$ test for unequal variances.

\section{Results}

\section{Gross Examination and $\mathrm{X}$-ray Findings}

SVD was observed in 8 ( 1 of 831 aortic and 7 of 551 mitral) explants in place for a mean of $136.0 \pm 22.67$ months (range 101 to 163 months) $[P$ (Fisher) $=.008]$.

- Dystrophic calcification (4 explants, 1 aortic and 3 mitral) led to reoperation after 113, 101, 133, and 145 months, respectively. Coarse calcific vegetations with severe stenosis were observed in a mitral case (Figure 1), while body cusp perforation (Figure 2) and commissural tearing with incompetence or steno-incompetence occurred in the remaining 3 cases with $\mathrm{x}$-ray scores ranging from 3 to 4 .

- Primary, non-calcium-related tearing occurred in 3 mitral cases after 121, 156 (Figure 3, $a$ and $b$ ), and 163 months. Pinpoint calcification (score 1) was observed in each, but was not located near tearing.

- A commissural dehiscence, consisting of a detachment of the commissural aortic wall from the stent post not related to calcification or infection, was the cause of incompetence in a mitral bioprosthesis at 156 months after implantation.

Nine bioprostheses, 7 mitral and 2 aortic, in place for a mean of $57.66 \pm 44.92$ months (range 3 to 122 ) showed no evidence of structural valve deterioration. Four were explanted because of paravalvular leak after 3, 16, 93, and 106 months (mean $54.5 \pm 52.5$ ), and 5 were prophylactically replaced in the setting of other cardiac surgical valve procedures after $3,42,55,79$, and 122 months (mean $60.2 \pm$ 44.1). All had pliable cusps with negligible pannus and no tearing. Four of 9 showed no calcification (score 0 at x-ray) at a mean time of $19.25 \pm 24.6$ months (range 3 to 55), and 5 showed initial commissural mineralization (scores 1 to 2 ) (Figure $4, a$ ) at a mean time of $88.4 \pm 30.4$ months (range 42 to 122 ).

Lipid insudation in the form of yellow spots was observed by the naked eye in 15 explants (Figure 5, a). In 2 explants it was so prominent that most probably accounted for cusp tearing, in the absence of any other explanation.

\section{Microscopic Findings}

At histology fibrinous lining on the cusp surface was focally present in all cases. A mild fibrous sheathing at the base was frequently evident and at transmission electron microscopic examination consisted of myofibroblasts enmeshed in collagen fibers. The surface lacked a true reendothelialization, occasionally showing lining of platelets.

Focal or scattered mononuclear infiltrates were observed in all cases just underneath leaflet surface; in only 1 explant they were seen also deep in the spongiosa.

At transmission and scanning electron microscopic examination, the elastic and collagen fibers appeared to be fairly well preserved. In particular collagen fibrils were regularly banded and arranged in variously oriented fascicles. Native cellular component was poorly preserved.

Cholesterol clefts, sometimes surrounded by mononuclear with foreign body-type inflammatory infiltrates, were seen at histology in 15 explants (Figure 3,c and $d$, and Figure $5, b)$. At transmission electron microscopic examination, lipid insudation consisted of interstitial lipid droplets, cholesterol needles, and lipid-laden macrophages featuring foam cells (Figure 6).

Calcification was intrinsic and involved both the commissural and cuspal body levels (Figure $4, b$ ). In only 1 case was mineralization observed also upon mild fibrous pannus. In all cases positive on X-ray, calcification was found at the ultrastructural level both on cell debris and elastic-collagen fibers. In addition, calcospherulae and focal collagen calcification were observed also in 2 non-SVD cases even with score 0 at $\mathrm{x}$-ray. In one instance calcification occurred upon massive lipid insudation (Figure 5, $b$, and Figure 6, $c$ ). 


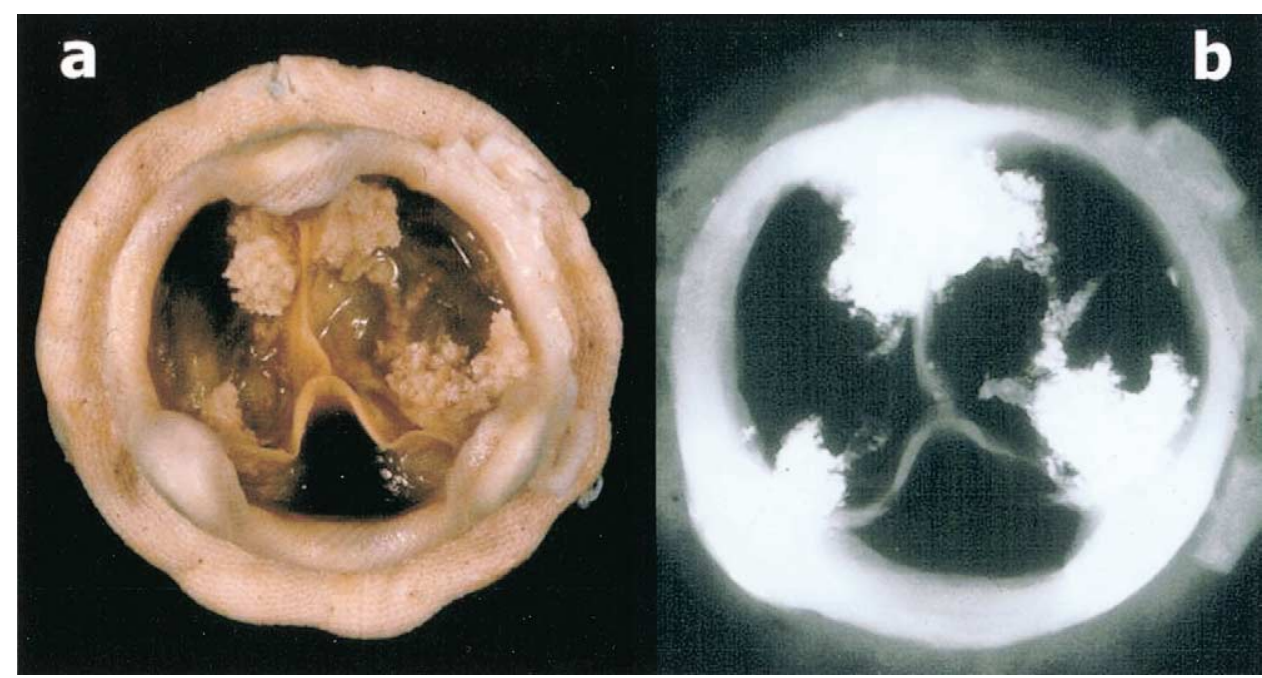

Figure 1. Coarse, polypous calcific deposits at all commissures in a mitral HCK II explant in place for 101 months. a, Gross outflow view. b, X-ray film.

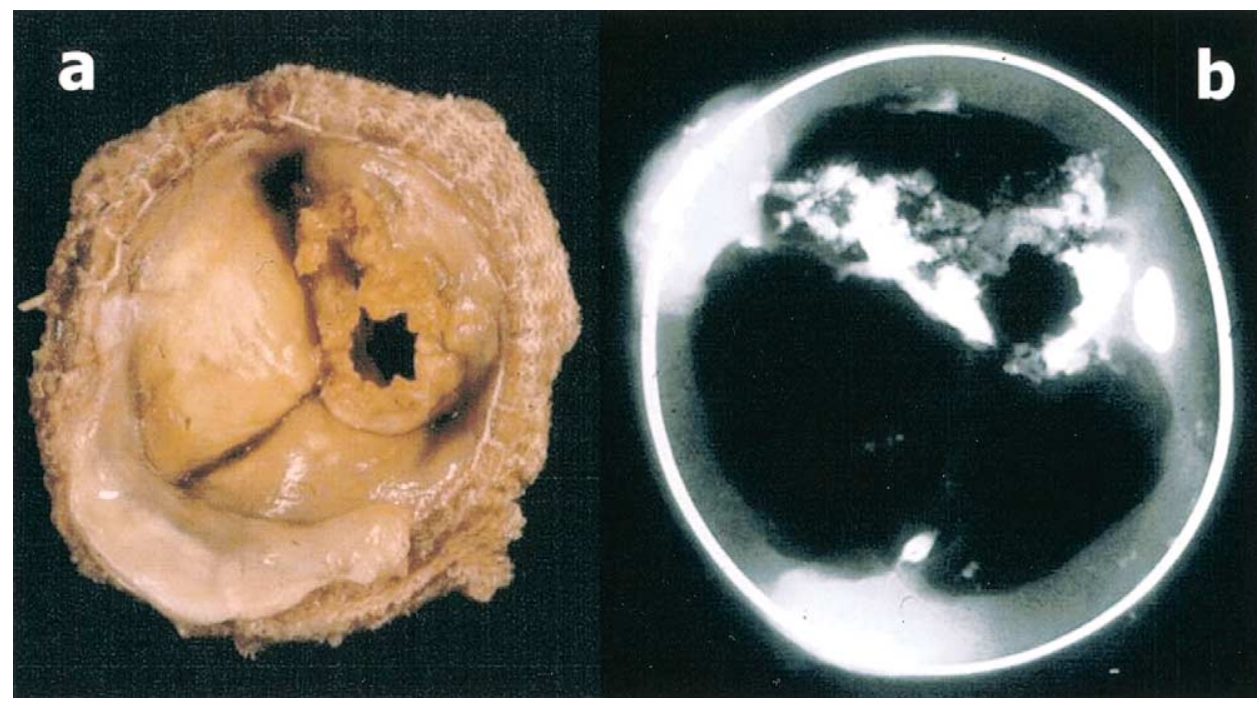

Figure 2. Calcification with body cusp perforation in an aortic HCK II explant in place for 113 months. a, Gross inflow view. $b, X$-ray film.

\section{Spectroscopic Findings}

Mean mineralization in non-SVD explants (prophylactic and paravalvular leak) was $14.70 \pm 22.23 \mathrm{mg} / \mathrm{g}$ versus $99.11 \pm 81.52$ of SVD explants $(t$ test for unequal variances $P=.128)$.

\section{Discussion}

The HCK Standard xenograft was the first commercially available glutaraldehyde-fixed bioprosthetic valve. Since the first implantation at the University of Padua in March $1970{ }^{7}$ hundred of thousands were used worldwide.
With time, pathologic studies of explants made clear that several complications influence bioprosthetic durability. ${ }^{8,9}$ In $70 \%$ of explants, failure was ascribed to dystrophic calcification, both in form of stiffness and tearing of the leaflets. ${ }^{10}$ All the HCK Standard explants, in place for more than 6 years, appeared more or less "mineralized." Dystrophic calcification appeared to be the main determinant limiting long-term performance, thus becoming a problem for both patient and surgeon. ${ }^{11}$ Energy dispersion analysis showed that the calcific deposits consisted of apatite crystals, ${ }^{5}$ and ultrastructural investigation demonstrated that 


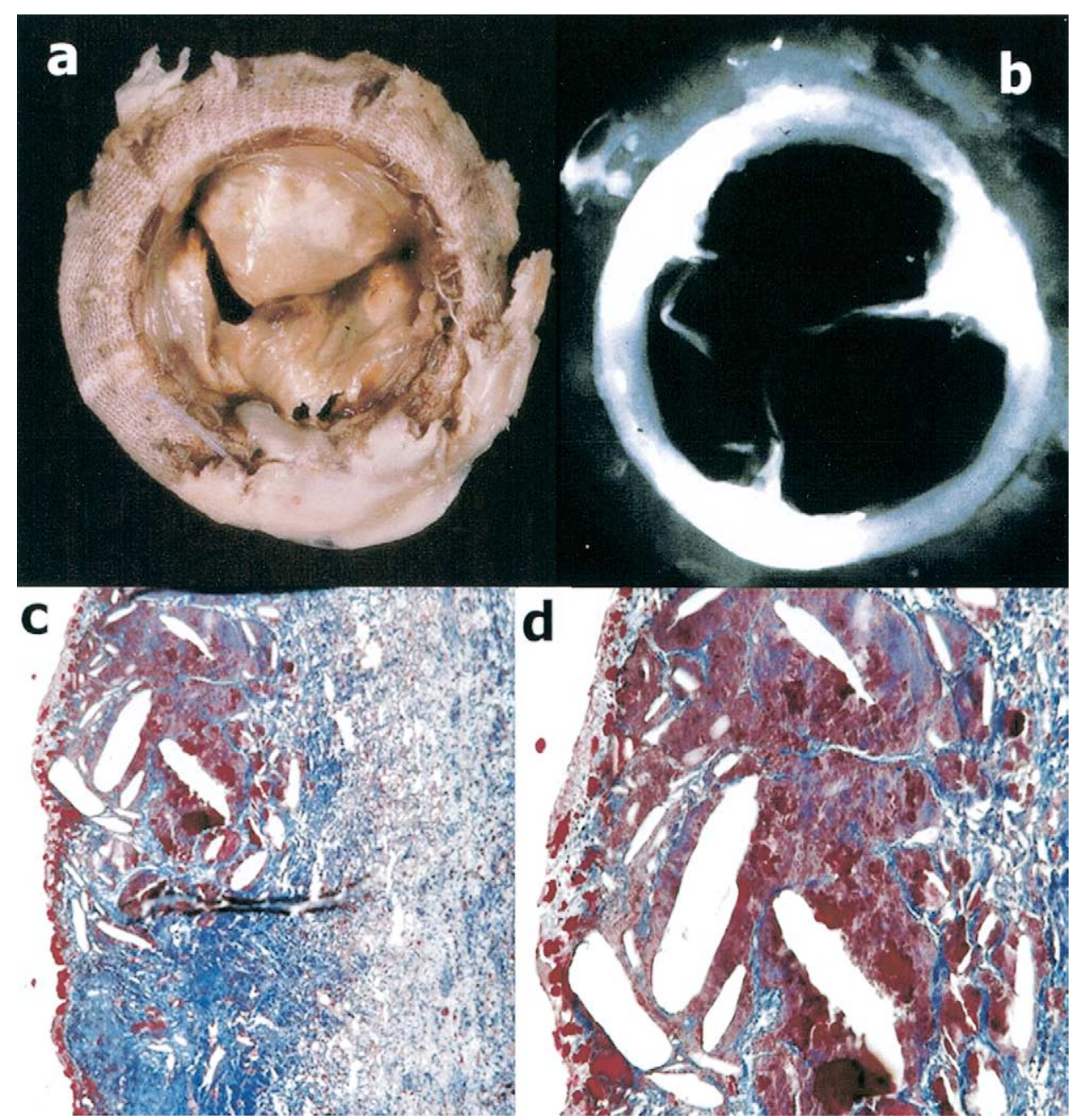

Figure 3. Non-calcium-related tearing in a mitral HCK explant in place for 156 months with massive lipid infiltration. a, Gross inflow view with yellow spots in the cusps and tearing. $b$, Negligible calcification on $x$-ray film. c, Cholesterol needles at histology (Azan stain $\times 18$ ). d, Close-up of $c$ (Azan stain $\times 36)$.

early nuclei of calcification occurred in the xenograft cell membranes and organelles, which were laden of phospholipids. ${ }^{5,12}$ The latter accounted for the phosphate component of apatite, whereas the calcium was derived from the extracellular compartment due to loss of membrane impermeability. ${ }^{13}$ Lessons from these pathological observations were incorporated into a second-generation valve, the HCK II, which was presented for the first time at the Second International Symposium on Cardiac Bioprostheses held in Rome in $1982 .{ }^{14}$ The efficacy of the antimineralization treatment was experimentally proved by subdermal ${ }^{15}$ and circulatory implants. ${ }^{16}$ Implantation in human beings started in 1982 and included the Toronto, Padova, and Treviso hospitals. Intermediate-term follow-up gave excellent results with $100 \%$ freedom from bioprosthetic failure at 8 years. $^{2,3}$
Bortolotti and colleagues, ${ }^{4}$ by comparing clinical outcomes of patients with HCK II with those of patients with the HCK Standard, were able to demonstrate a remarkable improvement in freedom from SVD at 8 years (100\% versus $78 \pm 4 \%$ in aortic, $100 \%$ versus $88 \pm 3 \%$ in mitral). The results might have been influenced by the age of the second series, since patients with HCK Standard differed significantly in mean age from those with HCK II ( $47 \pm 12$ versus $62 \pm 9$ years, $P<.001)$.

More recently, David and colleagues ${ }^{17}$ reported the results at 15 years with actuarial and actual freedoms from SVD of $81 \%$ and $90 \%$ in the aortic group and $66 \%$ and $83 \%$ in the mitral group, respectively, thus clearly demonstrating that HCK II is an improved version of first-generation porcine valve with extended durability. In particular, the results were excellent in patients 65 years or older, with 

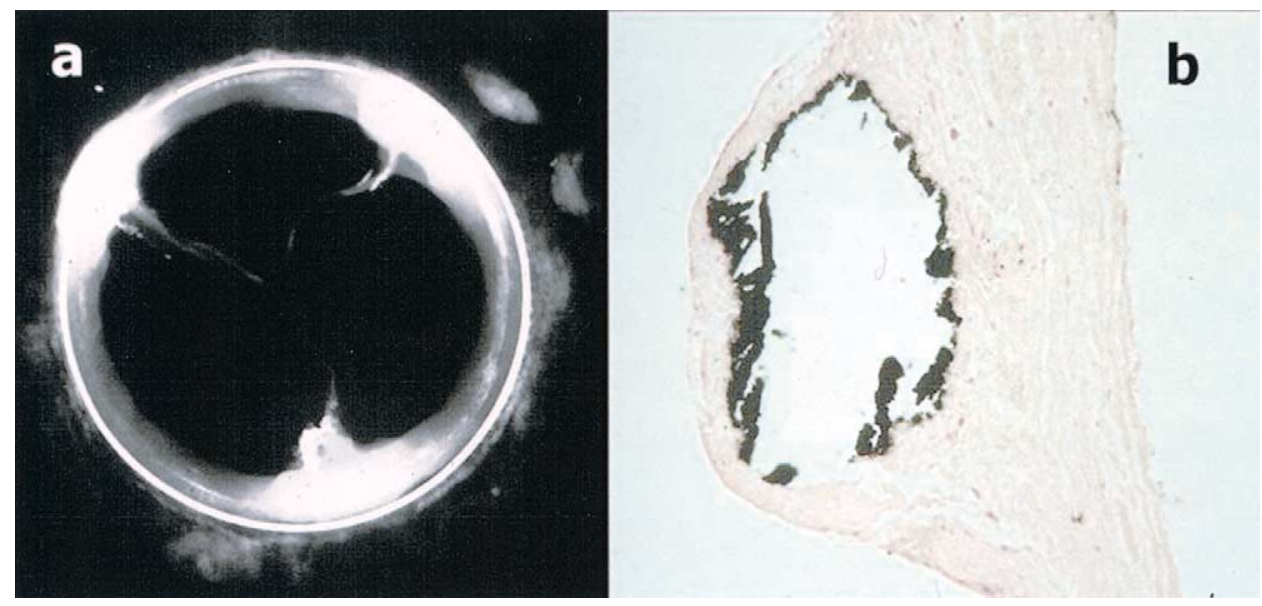

Figure 4. Mitral HCK II explant removed at 122 months from operation due to paravalvular leak. a, X-ray film showing pinpoint calcification at commissures. b, Nodular intrinsic cusp calcification at histologic examination (Von Kossa $\times 12$ ).

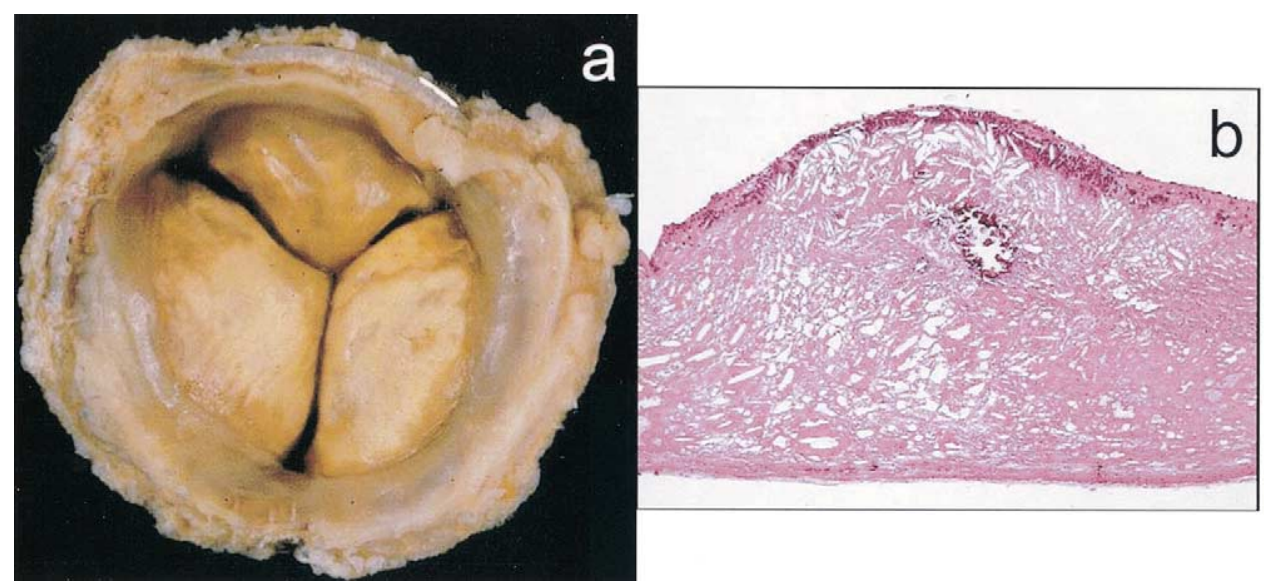

Figure 5. Prophylactically replaced HCK II aortic explant in place for 79 months. a, Yellow appearance of the inflow. b, Histology of a leaflet showing diffuse cholesterol clefts and small nodular calcification (hematoxylineosin $\times 18$ ). The adjacent section showed positive results at Von Kossa stain.

actual freedom from SVD at 15 years of $100 \%$ in aortic and $89 \%$ in mitral position.

Our clinical and pathologic experience confirms David's group's data that HCK II is a durable porcine valve, more so in the aortic than in the mitral position, as observed in other studies. SVD was rare and started to occur 2 to 3 years later than previously observed in HCK Standard. Valves in the mitral position began to fail structurally at 8.5 years postoperatively and valves in the aortic position did not deteriorate until 9.5 years postoperatively. One half of the SVD cases failed because of dystrophic calcification, in the usual mode of cusp stiffness or tearing. 8,9

Half of our specimens were explanted for reasons other than SVD: perivalvular leak and prophylactic removal. These explants were of particular interest because it was possible to detect early occurrence of dystrophic calcification, before overt dysfunction. Four of 9 did not show any evidence of calcification at $\mathrm{x}$-ray, whereas the remaining 5 exhibited pinpoint calcification at commissures as early as 42 months, with 1 explant prophylactically replaced after 10 years. Overall the amount of calcium content was quite low with a mean of $14.70 \pm 22.23 \mathrm{mg} / \mathrm{g} /$ dry weight versus 99.11 $\pm 81.52 \mathrm{mg} / \mathrm{g} /$ dry weight of failed bioprostheses. Evidence of early onset of calcification at the ultrastructural level was observed even in a couple of explants showing no mineralization on $\mathrm{x}$-ray. The finding of commissural calcification in explants without SVD confirms the view that mineralization starts at the commissural level long before commissural tearing, thus emphasizing the importance of mechanical stress in the onset of calcification. 


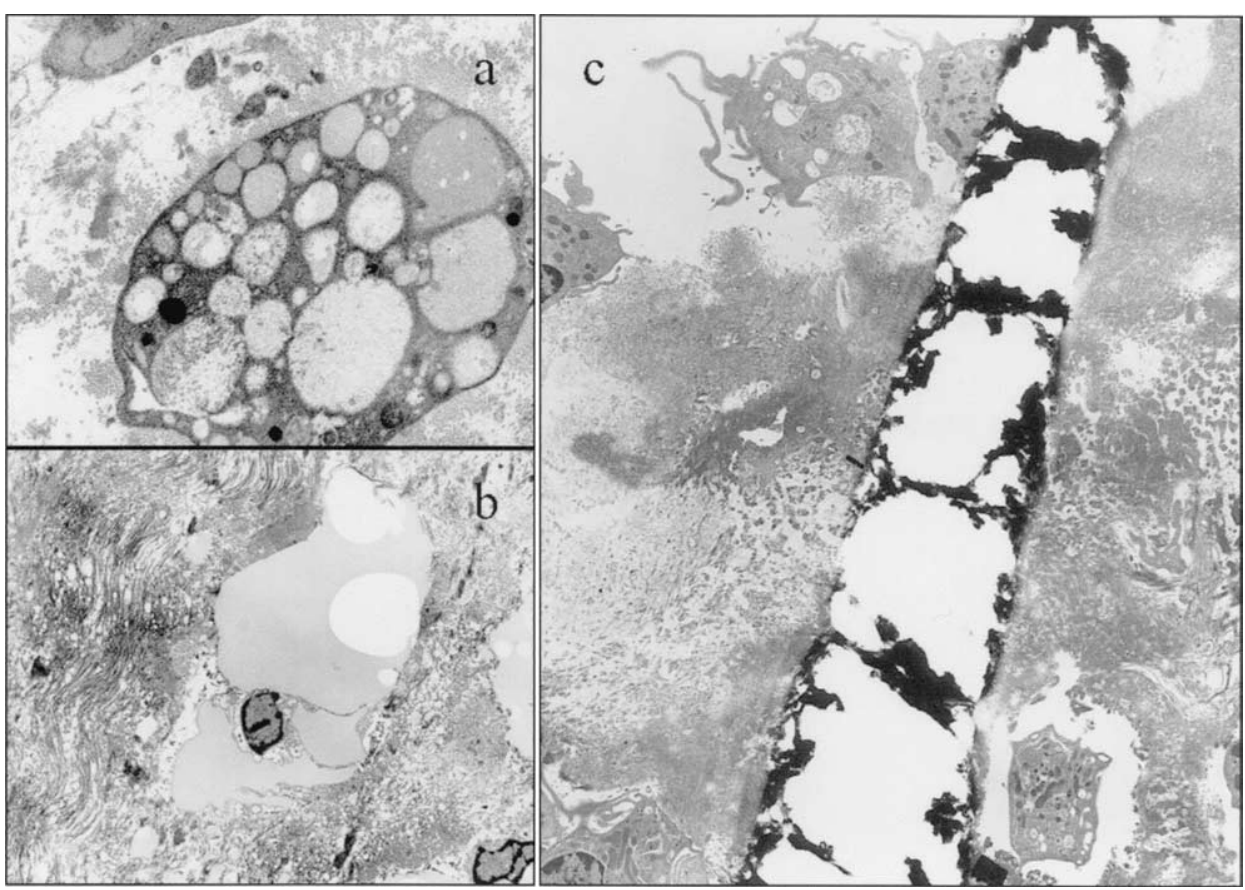

Figure 6. Electron microscopy of cusp lipid insudation. Lipid droplets are visible within the cytoplasm of macrophages featuring foam cells (a). Note lipid droplets also in the interstitium (b). A cholesterol cleft appears the target of mineralization in the same explant of Figure 5 (c).

All these observations support the clinical data of an effectiveness of T6 in delaying mineralization. Nonetheless, ultrastructural nuclei of mineralization were as usual, namely upon cell debris and collagen.

In contrast to Butany and colleagues, ${ }^{18}$ who reported severe pannus in $60 \%$ of failing valves, mainly in mitral position and often with pannus-related cusp tearing, we had no case of valve dysfunction due to fibrous tissue overgrowth. Butany and colleagues ${ }^{18}$ suggested that preservation at surgery of the subvalvular apparatus favored tissue ingrowth. This technique was less frequently employed in our study population.

Although the number of collected explants was limited, it is noteworthy that we never observed cases of ventricular free wall laceration, ${ }^{19}$ inward bending,${ }^{20,21}$ cuspal hemato$\mathrm{ma}^{22}$ spontaneous tearing of the cuspal muscle shelf, ${ }^{23}$ or thrombosis ${ }^{24}$ thus proving that the change of valve design led to substantial improvement with prevention of many other complications previously reported in HCK Standard. Interesting was the single case of commissural dehiscence, a complication reported in Carpentier Edwards porcine valve $^{25}$ but not in the HCK Standard. ${ }^{8,9}$

The most striking finding of our pathological study was lipid insudation, which was evident even by naked eye in the form of yellow spots. At light and electron microscopic examination, both interstitial lipid droplets and cholesterol needles as well as lipid-laden macrophages featuring foam cells were observed and probably accounted for primary tearing in 2 explants after 12 years of function. Thus lipid insudation and monocyte infiltrates occur in cuspal tissue of porcine bioprostheses as seen in early atherosclerosis and can precipitate SVD in the long-term, even in the absence of mineralization. ${ }^{26}$ A cusp torn at commissure by massive lipid infiltration was reported by our group also in the HCK Standard. ${ }^{27}$

T6 treatment removes the lipids from the pig valve at the time of commercial manufacturing ${ }^{28}$ but cannot prevent subsequent lipid insudation, which may also favor calcification. Clearly lipid insudation is an acquired, patient-related problem and as such would likely be seen with other valves. Thus, with T6 mitigation, dystrophic calcification may be delayed until other factors, such as lipid insudation, come into play.

Future prospective and randomized studies as well as clinical trials should include serum lipid assessment to establish whether this is a risk factor for SVD. Should a correlation between serum lipid and risk of SVD be demonstrated, then statins might be indicated in patients having porcine bioprostheses.

\section{References}

1. Wright JTM, Eberhardt CE, Gibbs ML, Saul T, Gilpin CB. Hancock II-An improved bioprosthesis. In: Cohn LH, Gallucci V, editors. 
Cardiac bioprostheses. Proceedings of the 2nd International Symposium. New York: Yorke Medical Books; 1982. p. 425-44.

2. Bortolotti U, Milano A, Mazzaro E, Thiene G, Talenti E, Casarotto D. Hancock II porcine bioprosthesis: excellent durability at intermediateterm follow-up. J Am Coll Cardiol. 1994;24:676-82.

3. David TE, Armstrong S, Sun Z. Clinical and hemodynamic assessment of the Hancock II bioprosthesis. Ann Thorac Surg. 1992;54:661-7.

4. Bortolotti U, Milano A, Mossuto E, Mazzaro E, Thiene G, Casarotto D. Porcine valve durability: a comparison between Hancock Standard and Hancock II bioprostheses. Ann Thorac Surg. 1995;60:S216-20.

5. Valente M, Bortolotti U, Thiene G. Ultrastructural substrates of dystrophic calcification in porcine bioprosthetic valve failure. Am J Pathol. 1985;119:12-21.

6. Pettenazzo E, Deiwick M, Thiene G, et al. Dynamic in vitro calcification of bioprosthetic porcine valves: evidence of apatite crystallization. J Thorac Cardiovasc Surg. 2001;121:500-9.

7. Cevese PO, Gallucci V, Morea M, Dalla Volta S, Fasoli G, Casarotto D. Heart valve replacement with the Hancock bioprosthesis. Analysis of long-term results. Circulation. 1977;56:II111-6.

8. Thiene G, Arbustini E, Bortolotti U, et al. Pathologic substrate of porcine valve dysfunction. In: Cohn LH, Gallucci V, editors. Cardiac bioprostheses. Proceedings of the 2nd International Symposium. New York: Yorke Medical Books; 1982. p. 378-400.

9. Valente M, Minarini M, Maizza AF, Bortolotti U, Thiene G. Heart valve bioprosthesis durability: a challenge to the new generation of porcine valves. Eur J Cardiothorac Surg. 1992;6:S82-90.

10. Milano A, Bortolotti U, Talenti E, et al. Calcific degeneration as the main cause of porcine bioprosthetic valve failure. Am J Cardiol. 1984;53:1066-70.

11. Thiene G, Valente M. Calcification of valve bioprostheses: the cardiac surgeon's nightmare. Eur J Cardiothorac Surg. 1994;8:476.

12. Schoen FJ, Levy RJ, Nelson AC, Bernhard WF, Nashef A, Hawley M. Onset and progression of experimental bioprosthetic heart valve calcification. Lab Invest. 1985;52:523-32.

13. Giddens DP, Yoganathan AP, Schoen FJ. Prosthetic cardiac valves. Cardiovasc Pathol. 1993;2:167S-77S.

14. Cohn LH, Gallucci V, editors. Cardiac bioprostheses. Proceedings of the 2nd International Symposium. New York: Yorke Medical Books; 1982.

15. Lenz DJ, Pollock EM, Olsen DB, Andrews EJ, Murashita J, Hastings WL. Inhibition of mineralization of glutaraldeyde-fixed Hancock bioprosthetic heart valves. In: Cohn LH, Gallucci V, editors. Cardiac bioprostheses. Proceedings of the 2nd International Symposium. New York: Yorke Medical Books; 1982. p. 306-19.
16. Arbustini E, Jones M, Moses RD, Eidbo EE, Carroll RJ, Ferrans VJ. Modification by the Hancock T6 process of calcification of bioprosthetic cardiac valves implanted in sheep. Am J Cardiol. 1984;53:138896.

17. David TE, Ivanov J, Armstrong S, Feindel CM, Cohen G. Late results of heart valve replacement with the Hancock II bioprosthesis. J Thorac Cardiovasc Surg. 2001;121:268-77.

18. Butany J, Yu W, Silver MD, David TE. Morphologic findings in explanted Hancock II porcine bioprostheses. J Heart Valve Dis. 1999; 8:4-15.

19. Bortolotti U, Thiene G, Casarotto D, Mazzucco A, Gallucci V. Left ventricular rupture following mitral valve replacement with a Hancock bioprosthesis. Chest. 1980;77:235-7.

20. Schoen FJ, Schulman LJ, Cohn LH. Quantitative anatomic analysis of "stent creep" of explanted Hancock standard porcine bioprostheses used for cardiac valve replacement. Am J Cardiol. 1985;56:110-4.

21. Valente M, Bortolotti U, Thiene G, et al. Post bending of the polypropylene flexible stent in mitral Hancock bioprostheses. Eur J Cardiothorac Surg. 1987;1:134-8.

22. Thiene G, Bortolotti U, Talenti E, et al. Dissecting cuspal hematomas. A rare form of porcine bioprosthetic valve dysfunction. Arch Pathol Lab Med. 1987;111:964-7.

23. Valente M, Arbustini E, Bortolotti U, Talenti E, Thiene G. Perforation of muscle shelf of right coronary cusp causing acute regurgitation of porcine mitral xenograft. Am Heart J. 1984;108:180-3.

24. Thiene G, Bortolotti U, Panizzon G, Milano A, Gallucci V. Pathological substrates of thrombus formation after heart valve replacement with the Hancock bioprosthesis. J Thorac Cardiovasc Surg. 1980;80: 414-23.

25. Nistal JF, Hurle A, Gutierrez JA, Mazorra F, Revuelta JM. Commissural dehiscence of Carpentier-Edwards mitral bioprostheses. Explant analysis and pathogenesis. J Thorac Cardiovasc Surg. 1995;110:68895.

26. Ferrans VJ, Mc Manus B, Roberts WC. Cholesteryl ester crystals in a porcine aortic valvular bioprosthesis implanted for eight years. Chest. 1983;83:698-701.

27. Arbustini E, Bortolotti U, Valente M, et al. Cusp disruption by massive lipid infiltration. A rare cause of porcine valve dysfunction. $J$ Thorac Cardiovasc Surg. 1982;84:738-43.

28. Cunanan CM, Cabiling CM, Dinh TT, et al. Tissue characterization and calcification potential of commercial bioprosthetic heart valves. Ann Thorac Surg. 2001;71:S417-21. 